\title{
Research on the Innovation of College Students' Employment Guidance in the Age of Big Data
}

\author{
Wei Liu \\ College Student Employment and Entrepreneurship Guidance Center, Harbin \\ University of Commerce, No. 1 Xuehai Street, Songbei District, Harbin, 150028, \\ China \\ weiwei@hrbcu.edu.cn
}

\begin{abstract}
In today's society, people's cultural level has generally increased, and the number of college students has increased dramatically. As they walked out of the campus, they began to face employment problems. The contradiction between the employment difficulties of college students and the difficulty in recruiting employers has become increasingly prominent. The employment concept of college students is not the main reason, but the reason behind it is that colleges and universities are not in place for college students' career planning guidance. Colleges and universities should strengthen the guidance of college students' career planning, change the employment concept of college students, improve their employability and achieve accurate employment. The arrival of the "Internet + " era is an opportunity for college students' employment guidance. It can promote the reform and innovation of education. At this stage, college students have encountered many difficulties in employment, which has become a common concern of the state and society. In order to achieve high-quality employment and full employment, we need to adapt to the trend of the times, fully exploit and utilize the advantages of the "Internet +" era, so that they can be implemented in the employment guidance of college students, and realize the employment guidance work of college students.
\end{abstract}

Keywords: Internet+, Big data, Employment guidance

\section{The content of college students' employment guidance}

\subsection{Employment situation and psychological preparation guidance for college students}

In order to help college students make their life choices in the employment guidance of college students, they need to help them understand the characteristics of market demand, understand their employment prospects, enable college students to establish market awareness, and recognize their own advantages and disadvantages, so that college students can Adapt to the actual development of society. To carry out employment guidance work in colleges and universities, it is necessary to guide university students to clearly understand the current employment situation, and to have

Article history:

Received (April 18, 2019), Review Result (June 8, 2019), Accepted (July 22, 2019) 
a correct view of them, to prevent too high expectations of their own ability, to maintain a moderate sense of superiority, and to be not subject to the traditional concept of employment. The impact, in the actual employment path, we must persist in struggle, work hard, and be prepared to meet the employment competition. In addition, in the process of college students' career selection, they need to have a rational evaluation of themselves, fully analyze the various situations that may exist in the employment process, and be able to withstand successive changes in the face of difficulties, and prepare for employment. Maintaining a good psychological state is also helpful for successful employment of college students [1]. In employment guidance, it is necessary to pay attention to the psychological preparation of college students, so that college students can rationally analyze and scientifically choose in the face of opportunities, so that their knowledge capabilities can be used in a safe place, and reasonable treatment measures can be taken to reduce problems. The situation has happened. Psychological preparation mainly includes its own psychological literacy, professional ethics and role orientation [2]. It actively conducts psychological counselling for college students, so that it forms a correct employment concept and has a more optimistic psychological quality, thus better cooperating with social development. The needs of talents are consistent.

\subsection{College students' career planning and design guidance}

When college students are reading their own development direction and action plan to determine, they must not only consider the actual situation, but also need to conduct a scientific analysis of the various influencing factors. In order for college students to choose the right career and avoid blindly following, they need to set out reasonable development goals and directions based on actual conditions. It can be seen that it is very necessary to carry out career planning and design guidance. It has important practical significance for college students' career choice [3]. Only when students have a comprehensive and clear understanding of their own situation can they reasonably determine their career direction and complete professional design. In the process of comprehensive understanding of the self, it is necessary to conduct an in-depth and rational analysis of its own strengths and weaknesses, to clarify the level of its own ability, to plan the employment direction in combination with the original work experience, and to solve the confusion of "what can I do?" When you understand yourself, you can continue to improve your existing strengths, constantly enrich yourself, realize your own life value, and be aware of your own self. You must not evade the shortcomings of your existence. You can ask your family, Students and friends can also get scientific evaluations from professional consulting organizations [4].

\subsection{Guidance for college students' job search skills and employment policies}

It is worthwhile to guide the job-seeking skills of college students. It is a relevant skill in the application process, which brings a better impression to the candidates. On the one hand, it is necessary to guide the college students to master the correct application requirements, and to properly match the clothing and manage the external image. A certain impact, the fit of the application can make up for some of the applicant's own deficiencies, improve their temperament [5]. In addition, it is necessary to have an early understanding of the recruiting unit, understand its attributes and 
business scope, and understand the relevant information of job-seeking positions, so that you can be more confident in your application. The employment guidance work of college students is based on the corresponding employment policy. College students must clearly understand the relevant personnel regulations in the relationship of employment and employment, and understand the employment-related systems of the country and regions in the same year. Employment policy the certain benefits that can be provided to the college students in the employment stage, including relevant restrictions, can reflect the legal provisions on employment trends, and are closely related to the graduates facing graduation. When guiding the employment policy, it is necessary to prevent students from entering the blind spot and eliminate all kinds of doubts arising in the process of choosing a job. The school needs to organize the promotion of relevant employment policies and realize its own ideals and society on the basis of understanding the national employment policy. The organic integration of reality [6].

\section{The new characteristics of college students' job hunting under the influence of the Internet}

"90s" college students have become the mainstay of colleges and universities, and their employment situation is more and more severely affected by the total number of graduates and structural contradictions. To break through the employment dilemma of contemporary college students, it is necessary to "post-90s" college students from the Internet thinking. Analysis of job search characteristics. New media such as the Internet, blogs, and smartphones attract the most popular group of college students with their unique features and interactive experience. As of the end of 2013, the proportion of young Internet users using mobile phones, desktop computers and laptops was $86.3 \%, 71.2 \%$ and $51.2 \%$ respectively. Among them, the number of young mobile phone netizens has reached 221 million, an increase of 12.8 percentage points over the same period in 2012. The average weekly Internet access rate for young Internet users is 20.7 hours. Compared with 2012, college students increased their online time by 2.3 hours. "90s" college students are the priority experiencers in the Internet age, and they are happy to share their opinions and opinions on the Internet. In terms of job hunting, the network has had a profound impact on the employment outlook and job hunting behavior of "post-90s" college students. According to the "2013 Graduate Student Job Search Feedback Report" released by Renren School, the Internet has surpassed the traditional job fairs and campus presentations, and has become the most popular channel for 2013 resumes. The recruitment website has the highest usage rate, accounting for the whole. $70 \%$. After the "90s" college students are better at using the Internet to obtain employment information and carry out job hunting activities, such as through the online forum, the student's job search process microblog "live" and other forms of a more comprehensive understanding of employers. "After the 90s" college students creatively grafted online hotspot language and presentation methods into jobseeking packaging, such as "every object", "Taobao", "roaring body" became the popular language for job hunting in recent years; "micro resume", multimedia resume, etc. The job hunting forms are endless. Among them, the online post-90s job hunting video with the theme of "Jin Mailang" in 2013 is a typical example of Internet job hunting. On the one hand, the network satisfies the students' desire to reduce the cost of job hunting and improve the success rate of job hunting. On the other hand, it also has 
its own shortcomings. First, the network information is mixed, and the students who have developed for a long time do not know how to ask for "Tang Niang" (ie, through the network). Baidu search answer), look at the evaluation of netizens, rather than the habit of comprehensive evaluation based on their own actual situation, leading students to grasp the real and comprehensive information, lack of comprehensive understanding of job hunting positions. Second, with the development of Weibo and WeChat platforms and the improvement of functions, everyone can become a self-media. College students are not deeply involved in the world, lacking the ability to screen and discriminate online information. Faced with such complicated network information, especially graduates in the critical period of job hunting are more likely to fall into the trap of false network information. Third, students rely too much on online job hunting and neglect potential opportunities in job fairs. Fourth, in the face of the new recruitment methods of employers, many students have shown "unacceptable". For example, they will not design resumes suitable for mobile phone platform reading, and will not be suitable for remote interviews. Finally, the convenience of online job search reduces the cost of trial and error for students, and the concept of student employment changes. The phenomenon of graduates migrating frequently. In summary, guiding the college students to use the network as a double-edged sword is a new topic for the employment guidance department of colleges and universities.

\section{The enlightenment and new requirements of internet thinking on college employment guidance work}

"Internet thinking" is a hot topic in the society. The word was first proposed by Baidu founder Li Yanhong, referring to the market, users, products, and enterprises in the context of the continuous development of technologies such as (mobile) Internet, big data, and cloud computing. The value chain and even the way in which the entire business ecosystem is re-examined. Internet thinking has a major impact on entrepreneurship, business operations, and corporate management.

\subsection{Characteristics of internet thinking}

Internet thinking has five distinctive features: First, it is instant and convenient, that is, the information transmission and acquisition of the Internet is faster and richer than the traditional way. Second, the degree of freedom of expression, that is, the emergence of the Internet and self-media makes people more likely and more willing to express or express themselves. Third, free, customizable, you can customize a personalized free information push mechanism according to user needs. Fourth, big data thinking, mobile Internet provides the possibility of collecting big data, data acquisition is more convenient, and the important value of data analysis and prediction is more prominent. Although there is still no unified view on the definition of big data in the academic world, Gartner Group, which is engaged in big data application research earlier in the industry, believes that the so-called big data requires a new processing model to have stronger decision-making power, insight and process. Optimized capacity, high growth rate and diversified information assets, big data analysis can be applied to many areas such as disease control, customer behavior prediction, etc., and has immeasurable value. Finally, focusing on the user experience, the Internet has a more friendly interface, faster functional links, and stronger interactive design. Sweeping and shaking has become a typical interactive experience that customers love to see. In a word, Internet 
thinking emphasizes the segmentation of customer groups, personalized services and value of people to meet the needs of different groups of people, to maximize the value of people, economic and social benefits.

\subsection{New requirements for internet thinking on employment guidance in colleges and universities}

Under the influence of Internet thinking, employers pay more attention to the integration of recruitment platforms and resources, such as the compression recruitment process, flat recruitment management, adding WeChat QR code to recruitment posters, developing a network job search system, and increasing the interactive experience of employers and students. Create a WeChat network application platform, and strive to achieve accurate job matching on the fingertips, improve recruitment efficiency. Large companies such as Alibaba have tried to develop mobile test systems (ie, mobile smart terminal-based test products), allowing job seekers to access, submit job search materials, and even take exams anywhere through new media such as mobile phones. Employers can use the mobile network to achieve integrated mobile recruitment, interview scheduling, interview feedback, online written test, online marking and other functions.

It is not difficult to see that the employer is trying to adapt to the new characteristics of the post-90s college students' job hunting, actively adjust the recruitment method, improve the matching of personnel and reduce the recruitment cost. Internet thinking has created a win-win situation for employers and job seekers, and has satisfied both parties' pursuit of efficiency. These new changes have put new demands on the traditional employment guidance work of colleges and universities. For colleges and universities, the network platform has greatly solved the dilemma of insufficient teachers due to the expansion of the school, and formed an online and offline interactive employment guidance pattern that the school actively guides and students self-help. However, under the new situation, the employment guidance department of colleges and universities still needs to conduct dynamic research, research and judgment on the recruitment methods of employers and the characteristics of student job hunting, and use Internet thinking to promote innovation in employment guidance.

\section{The "90s" college students' employment guidance work innovation under the internet thinking}

The current employment guidance work environment is facing new changes. The popularity of smart phones and $4 \mathrm{G}$ networks is there. There are changes in the thinking and behavior characteristics of college students after the "90s", and the school raises the domestic demand for the quality of personnel training. The employment guidance work of colleges and universities should conform to the requirements of the times and the characteristics of students, use Internet thinking to solve the dilemma of employment guidance, and construct a three-dimensional employment guidance system with high information, interaction and convenience.

\subsection{Establishing a large database, realizing the scientific guidance of employment guidance, and feeding back the cultivation of talents in colleges and universities}

For colleges and universities, employment is an important part of education. The quality of employment highlights the quality of school personnel training, which in turn 
affects enrollment. Therefore, colleges and universities should establish a large database to provide scientific guidance and support for data training and employment guidance for schools through the collection and analysis of data. Victor Meyer Schonberg, author of "The Big Data Era: The Great Revolution in Life, Work, and Thinking," believes that future trends can be predicted by analyzing the correlation between massive amounts of data. In terms of employment, big data can present the status quo of labor supply and demand and shortage, turnover rate, unemployment rate, satisfaction, salary and welfare, and even predict future trends. Therefore, the active use of big data is the basic idea necessary for modern university education and employment guidance.

\subsubsection{The value of mining data in employment guidance}

On December 6, 2013, the Ministry of Education issued the "Notice of the Ministry of Education on Doing a Good Job in the Employment of Graduates of Regular Colleges and Universities in the Whole Country of 2014", requiring all colleges and universities to gradually release the annual report on the employment quality of graduates from the school from 2014, and It will be announced on the campus network, employment network, the national three-dimensional platform for employment of public service for college students or other media, and gradually establish an annual report system for the employment quality of college graduates. This is an attempt to break the barriers to information and make a horizontal and vertical comparison of talent training and employment quality in colleges and universities. In order to maximize the value of data in employment guidance, we must first evaluate and analyze the quality of students' quality through online teaching and evaluation platforms before students pursue job hunting, and form a model of students' quality ability models. Customized quality training provides scientific data support for the school's talent training model innovation. Secondly, with the support of the mobile Internet, colleges and universities can create a more practical and intimate one-stop employment service platform, and collect data on students' employment information, registration and recruitment activities, through the job application process, career choices, etc. The integration of data, understanding the problems and characteristics of students' job hunting, analyzing and predicting students' job-seeking behavior, providing a basis for timely intervention of employment guidance services and scientific employment guidance. Finally, after the employment guidance service is completed, the electronic questionnaire can be used to generate the QR code (the QR code is generated by the address of the electronic questionnaire, and the student uses the smart phone to scan the QR code into the mobile browser to fill in the questionnaire) for quality feedback. After the students submit the questionnaire, the results are displayed in real time by the data back ground, saving time and manpower of the statistical data. This kind of real-time data feedback on the quality of employment guidance will help to explore the embedded, full-scale employment guidance work model and improve the quality of employment guidance services.

\subsubsection{Realize the data linkage between universities, government and social organizations.}

Government agencies and social organizations collect and store a large number of public data resources related to employment, such as salary data of social security management agencies, human resources social security statistics of human and social 
departments, and cities. The data on the supply and demand of public employment service organizations, the labor supply and demand data of talent management institutions, etc. These data samples are large in volume and highly credible, and can be described as "data gold mines". At present, many government agencies and social organizations are gradually promoting information disclosure, information exchange, sharing and analysis systems. Universities can actively connect with governments and social organizations, open up information sharing with social data resources, and improve the effectiveness of employment guidance.

\subsubsection{Paying attention to the data survey of industry and post, and judging the rational employment are inseparable from the analysis and grasp of the labor market.}

In order to understand the current situation and future trends of supply and demand in different industries and positions, various provinces and universities have made useful attempts. For example, the Guangdong Provincial Department of Education has organized the "Industry-Professional-Employment Analysis Competition" for college students, guiding students to analyze the employment situation through industry and post dynamic data analysis, and rationally adjust employment expectations. Employers can also rationalize the employment plan for the professional, geographical and gender distribution of graduates to avoid high consumption of talents.

\subsection{Starting from the pain points of students, carrying out diversified and efficient employment guidance work}

The employment guidance department of colleges and universities should address the pain points and needs of students in the employment guidance, and provide students with multiple and efficient employment guidance services, which truly reflects the students-oriented and can get the students' favor and participation.

\subsubsection{Create a reliable and realistic employment information push platform to realize private subscription of employment information}

At present, "post-90s" college students lack a reliable and realistic employment information push platform, and lack of customizable employment guidance services and coping strategies for new recruitment methods. The employment guidance department of the university should take the initiative to integrate resources with relevant departments, simplify the process, strengthen the connection between work and network, and develop a self-help information employment guidance platform for employers and students. For example, through the addition of functions, the employer can pass the school employment guidance information website self-publishes recruitment information, and finds matching graduate information through keyword search. At the same time, the employment guidance department should also strengthen contact with employers, combine new types of recruitment and interview methods, timely improve and upgrade the methods and contents of student guidance, and increase the skills of new recruiting methods such as mobile resume production counseling and online interview counseling and training. For example, Tsinghua University upgraded the employment network in 2013, and built a "one-two-wing" information platform based on the graduate employment network, mobile platform and social network to provide students with comprehensive and efficient employment guidance services. In 
response to the lack of students' interview skills, Tsinghua University has launched the "4S Plan" to improve students' interviewing skills through student simulations and observer feedback. Secondly, the employment guidance department can combine the language characteristics and information reading habits of the "post-90s" students, reintegrate, design, and package the recruitment information, publicity and presentation methods, and attract students' attention with the language that students like. Such as creating a work city APP or employment guidance department WeChat public account, to carry out immediate and efficient employment guidance information push, let employers and students better understand the employment guidance department, do a good job in campus recruitment services.

\subsubsection{Make full use of the mobile Internet to carry out employment guidance work in a diversified and efficient manner}

With the popularity of the mobile internet, smart phones have become a new carrier for job guidance. According to statistics, in 2013, there were 116.96 million new mobile phone users in China, reaching 1,291,100,000 at the end of the year, including 40.61 million mobile phone users. The telephone penetration rate reached 110.5/100 people. Among them, the number of mobile Internet users is 500 million. Under the promotion of digital campus and campus WIFI signal, college students can use mobile Internet for online recruitment, remote video interview, career consultation appointment, and career evaluation, to achieve quick and convenient communication between employers, students and universities. At the same time, relying on the mobile Internet employment guidance, students can receive personalized guidance and services while sitting in the dormitory. This method is more in line with the behavior characteristics of the "post90 s" college students, and it is also more private.

\subsection{Divide the student groups and make full use of the fragmentation time of the students to carry out employment guidance services}

The post-90s college students have different needs for employment guidance. The college employment guidance department needs to segment groups according to the students' ability and quality and employment guidance needs, and provide targeted counseling, individual counseling, student assistant groups, peer education. And other forms of employment guidance services.

\subsubsection{Grasp the hardware construction of network employment guidance work}

At present, some colleges and universities have not yet achieved full coverage of the campus network, and some colleges have not introduced a paid professional profession assessment system, but borrowed a free online professional assessment system. The incompetence of hardware limits the innovation of employment guidance work, resulting in a passive situation of powerlessness. To solve this dilemma, we must first increase investment in building a network interactive platform. The recruitment of employers in the future will break the geographical boundaries. The employment guidance department needs to prepare for the new recruitment methods such as online interviews and online exams, and reduce the cost of job hunting for students. Secondly, we must make efforts to make the employment guidance work website not only publish employment information, but also a richer, more three-dimensional, more humanized 
guidance platform, such as constructing a career education and employment guidance before the students to learn independently, and the teachers are personalized in the class. After class, students complete the full employment guidance mode of online operation. The advantage of this online and offline combination of employment guidance mode is that students can master the progress of learning according to their own situation and enhance the initiative of learning. In addition to network hardware, schools also need to provide venue support for counseling and group coaching to achieve hierarchical classification and accurate career guidance. For example, first-year students can share their interest and share career planning concepts through topics such as online school and career planning. Students in the second to third grades can guide students to participate in classroom teaching, online self-study and second classroom activities through career planning competitions and professional analysis competitions. Fourth-grade students can participate in group counseling for employment skills improvement. Finally, it is necessary to seize the fragmentation time of the students. Microblogging, WeChat, Michao and other communication methods have subverted the traditional way of information dissemination with rapid and diversified characteristics. Students only need to move the mouse or press the button of the mobile phone to find the required information and materials. Providing new channels and new positions, it has also become the new favorite of corporate recruitment. For example, "micro recruitment", "micro resume" and "micro job search" are the new trends of current recruitment. The employment guidance department of colleges and universities should take the initiative to study the new situation and realize the employment guidance "small but fine" and "small and beautiful". For example, Beijing Forestry University has vigorously carried out the "micro-counselling" of college students' career development in recent years, and realized more than the traditional employment guidance courses. Interaction, point and face combination, and strive to make each student have a "employment guidance commissioner" to improve the coverage of employment guidance work.

\subsubsection{All departments of the school work together to strengthen software construction}

Realizing the informationization of employment services, hardware is the foundation, and software is the soul. To achieve innovative employment guidance work ideas, to achieve the dividend of Internet thinking, but also have the courage to accept new things, dare to use the new things mentality, work hard in software. At present, although some colleges and universities have microblogs and WeChat public service platforms for employment guidance, there are also colleges and universities that are reluctant to provide school organization codes for information security and liability risks during certification, which makes information release and functional development limited. The value of online employment guidance cannot be maximized.

Second, we must strengthen the training of the teaching staff. The professional team is the basis for scientific and efficient employment guidance. Increase training, improve the quality of the employment guidance team, introduce highly educated and technically savvy talents (such as those with the ability to analyze data), and improve the information literacy and professional level of the faculty to provide students with closer needs and more Efficient employment guidance activities. 
Finally, all departments of the school need to strengthen coordination and cooperation in strengthening students' integrity education, reducing mobile Internet access fees, student job search costs, and personal information protection.

\subsection{Paying attention to the user experience and enhancing the participation of teachers and students in employment guidance}

Paying attention to user experience is a major feature of Internet thinking. Employment guidance requires the participation of teachers and students, and even the government and employers. Therefore, it is necessary to integrate existing resources and open up communication channels between students, schools and employers. For example, through school organization simulation interviews, corporate visits, etc., students can deepen their understanding of employers, establish labor relations on the basis of mutual understanding, and reduce unnecessary turnover behaviors caused by students' high expectations before employment. For example, refer to the network simulation entrepreneurial experience in entrepreneurship training, develop network simulation work experience of different occupations, and enhance students' feelings and understanding of career intuition. For another example, employment guidance personnel should take the initiative to learn the Internet thinking, and actively transform and upgrade the employment service process in accordance with the requirements of students and employers to provide better employment services for both parties.

Improving the quality of employment is a matter of people's livelihood. The report of the party's 18th National Congress pointed out that it is necessary to "promote higher quality employment." At present, the coverage of China's 4G network and smart products has become a fixed trend. College students have shown new changes in their thinking, employment concept and behavior. The employment guidance department of colleges and universities, as an important hub for connecting students and employers, must use Internet thinking. Do a good job in research and service for employers and "post-90s" college students. On the basis of research, innovate work ideas, and build an interactive, immediate and efficient three-dimensional employment guidance system to better connect students and employers and enhance employment. Guide the quality of service and highlight the value of employment guidance.

\section{References}

[1] Chen Yong, Lu Na, Li Sheng, and Chen Ting, "The improvement of the professional ability of college counselors under the new media environment," Journal of Chongqing University of Technology (Social Science), no.7, (2014)

[2] Jiao Jia, "Research on the path of professional ability improvement of college counselors," Ideological and theoretical education, no.9, (2016)

[3] Zhou Xing, "The improvement of the professional ability of college counselors under the Internet thinking," Exam Weekly, no.14, (2016)

[4] Chen Liju, "Research on the path of college counselors' professional ability improvement under the new media environment," Journal of Hubei Second Normal University, no.21, (2016)

[5] Yang Xiaoqing and Zhao Yuwen, "Research on the professional ability construction of college counselors in the era of "Internet +"," School Party Building and Ideological Education, no.16, (2016)

[6] 2013 China Youth Online Behavior Survey Report [EB/OL], (2013) 